\title{
Extracorporeal Membrane Oxygenation
}

Aybuke Kekecoglu ${ }^{1}$, Cengiz Ozdemir ${ }^{2}$, Levent Karasulu ${ }^{2}$, Orcun Unal ${ }^{3}$, Zeynep Nilgun Ulukol ${ }^{4}$, Bakan ND ${ }^{2}$, Fadime Kelesoglu ${ }^{1}$, Burcu Arpinar Yigitbas ${ }^{* 1}$ and Kosar $\mathbf{A F}^{1}$

${ }^{1}$ Department of Respiratory Intensive Care Unit, Yedikule Chest Disease and Surgery, Training and Research Hospital, Istanbul, Turkey

${ }^{2}$ Department of Chest Disease, Yedikule Chest Disease and Surgery Training and Research Hospital, Istanbul, Turkey

${ }^{3}$ Department of Cardiovascular Surgery, Istanbul University, Istanbul Medical Faculty, Istanbul, Turkey

${ }^{4}$ Department of Anesthesia and Reanimation, Istanbul University, Istanbul Medical, Istanbul, Turkey

"Corresponding author: Burcu Arpinar Yigitbas, Department of Chest Diseases, Yedikule Chest Disease and Surgery Training and Research Hospital, Istanbul, Turkey, Tel: +905336653549; E-mail: drburcuayigitbas@yahoo.com

Received date: Dec 29, 2014, Accepted date: Jan 02, 2014, Published date: Jan 04, 2014

Copyright: ( 2014 Yigitbas BA, et al. This is an open-access article distributed under the terms of the Creative Commons Attribution License, which permits unrestricted use, distribution, and reproduction in any medium, provided the original author and source are credited.

\section{Clinical Image}

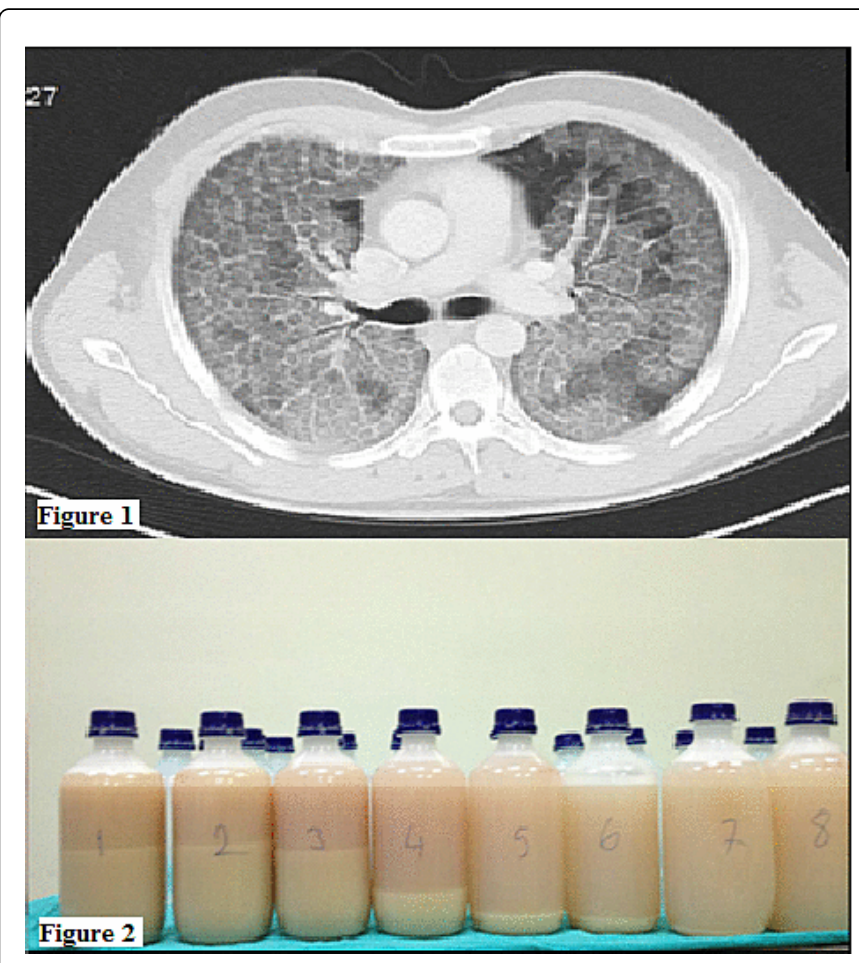

A 33-year-old male patient was referred to our hospital with the complaints of coughing, shortness of breath and respiratory distress present for the last three years, deteriorated within the last three months. He was not a smoker. Respiratory rate was $45 /$ minute. Oxygen saturation $74 \%$ with $12 \mathrm{~L} / \mathrm{min}$, arterial blood pressure 130/86 $\mathrm{mm} / \mathrm{Hg}$ and heart rate was $95 / \mathrm{min}$. End-inspiratory rales were heard over all zones bilaterally. Laboratory parameters were normal. Arterial blood gas measurements were as follows in ambient air. Ph: 7.4, $\mathrm{PaO}_{2}$ : $36 \mathrm{~mm} / \mathrm{hg}, \mathrm{PaCO}_{2}: 32 \mathrm{~mm} / \mathrm{Hg}$. On chest X-ray, bilateral widespread alveolar infiltrations, ground glass, and crazy paving appearance were detected.

Patient was entubated in our intensive care unit. No microbial growth was found in blood, urine and sputum cultures. Bronchoalveolar lavage fluid was obtained from middle lobe of the right lung; PAS (+) alveolar proteinosis was detected. İt was decided to carry out total bronchoalveolar lavage of the right lung first in combination with ECMO. Total lung lavage was carried out at sevenday intervals. The patient was extubated on the same day. His oxygen saturation level increased to 95 percent. On chest X-ray and thorax $\mathrm{CT}$, regression was seen. Patient was discharged from the intensive care unit with oxygen support and lung transplantation was recommended. Although natural history of PAP is variable, one third of the cases may die due to progressive hypoxemia and intervening secondary infections. In cases with severe hypoxemia which can not be improved despite mechanical ventilation support, whole lung lavage with the accompaniment of ECMO may be lifesaving (Figures 1 and 2). 